\title{
Association of active coping to unfair treatment with perceived stress and depressive symptoms in African Americans: mh-grid study
}

\author{
Ayomide R. Ojebuoboh ${ }^{*}$, Amparo G. Gonzalez-Feliciano², Kristen M. Brown², Rumana J. Khan², Ruihua Xu²,
} Lisa A. DeRoo², Jessica Lewis², Rakale C. Quarells ${ }^{3}$ and Sharon K. Davis²

\begin{abstract}
Background: Unfair treatment such as discrimination and racism contribute to depression and perceived stress in African Americans. Although studies have examined how responding to such treatment is associated with ameliorating depressive symptoms and levels of perceived stress, most do not focus on African Americans. The purpose of this study is to assess how talking to others in response to unfair treatment is associated with self-reported depressive symptoms and perceived stress levels in African Americans.

Methods: A sample from the 2010-2013 Minority Health Genomics and Translational Research Bio-Repository Database was used and consisted of 376 African American adults aged 30-55 years old residing in the southern region of the United States. Linear regression models were used to assess the association between talking to others following unfair treatment, compared to keeping it to oneself, on self-reported depressive symptoms and perceived stress. The predictor variable was based on the question "If you have been treated unfairly, do you usually talk to people about it or keep it to yourself?".

Results: Talking to someone after being treated unfairly was inversely associated with perceived stress ( $\beta$ : -3.62 , SE: $1.14, \mathrm{p} \leq 0.05)$ and depressive symptoms ( $\beta$ : -3.62 , SE: $1.14, \mathrm{p} \leq 0.05)$.

Conclusions: African Americans who talked to others in response to unfair treatment had lower depressive symptoms and perceived stress than those who kept it to themselves. More outreach to African Americans regarding the importance of talk in response to exposure to unfair treatment is needed as a potential coping mechanism.
\end{abstract}

Keywords: Unfair treatment, Depressive symptoms, African American health, Perceived stress, Talking, Active coping

\section{Background}

African Americans continue to face disproportionate experiences with unfair treatment, racial discrimination and unequal access to healthcare and other necessary resources [1-5]. This negative impact on the health of African Americans includes overall lower quality of

\footnotetext{
${ }^{*}$ Correspondence: ayomide123@gmail.com

1 University of Minnesota Medical Scientist Training Program, 420

Delaware St SE, Minneapolis, MN 55455, USA

Full list of author information is available at the end of the article
}

life and high prevalence of low-quality sleep and narcolepsy, which is associated with biological dysregulation and subsequent allostatic load [6, 7]. African Americans exposed to mistreatment due to perceived racial discrimination have a higher average diastolic blood pressure reactivity compared to those who did not face mistreatment due to perceived racial discrimination [8]. Since stress due to discrimination plays a role in the physical and mental health of African Americans, it is important to examine methods that can alleviate perceived stress in African Americans [9]. 
In addition to increased perceived stress, African Americans also have a higher likelihood of suffering with more severe and long-term depression [10, 11]. There are many factors including discrimination, socioeconomic status, systemic racism in the medical community and stressful life events that contribute to depression in African Americans [11].Since depressive symptoms can be a precursor for the future development of Major Depressive Disorder (MDD), it is important to determine ways to ameliorate depressive symptoms in African Americans order to prevent the chronicity of MDD.

Research has explored different coping mechanisms used to reduce perceived stress in African Americans like interpersonal support, disengagement coping and emotion-focused coping [12-15]. There are many studies that have examined how African Americans cope with racism and discrimination [16-19]. Although racism and discrimination are a form of unfair treatment, other papers have focused more on coping mechanisms in response to racism and discrimination and not unfair treatment per se. The John Henryism scale, which represents highenergy/high effort coping, is an effective tool that has been used to show how certain coping methods can alleviate stress among African Americans [16]. This scale examines three themes: 1) efficacious mental and physical vigor, 2) a strong commitment to hard work and 3) a single-minded determination to succeed [16]. Previous research has shown the association between John Henryism and systolic blood pressure reduction for African American men [20]. It can also be a moderator for the association between race-related stress and rumination [16]. Additionally, disengagement coping has been shown to partially mediate the association between depressive symptoms and the Strong Black Woman Complex Africultural Coping Systems Inventory is another measure that has been used to represent culture-specific coping strategies that African Americans use during stressful situations [21]. Prior research has also shown that spiritual well-being can partially mediate the association between Africultural Coping Systems Inventory, and quality of life [22].

While there is more focus on examining coping mechanisms for stress, there is more emphasis on examining treatment options for depression, like antidepressants, electroconvulsive therapy (ECT), selective serotonin reuptake inhibitors (SSRIs), and psychotherapy [23]. Psychotherapy, which is also called talk therapy, has shown strong evidence of reducing depressive symptoms [24]. However, many of the discussions on psychotherapy have focused on African Americans' perspective on psychotherapy, instead of how it could be used as a strategy in alleviating depressive symptoms [25]. Encouraging social support is another way to address both depressive symptoms and perceived stress levels in African Americans, as evidence shows social support plays a positive role in lessening perceived stress and depressive symptoms in African Americans [26, 27]. Specific types of social support like emotional and instrumental support can also lead to different outcomes on perceived stress [28]. While emotional support consists of going to friends and family about one's problems, instrumental support involves family and friends completing actions [28].

Although social support has been studied extensively among African Americans, most studies have examined overall social support and not the association of talking which is emotional support $[29,30]$. The focus of this project differs in that we focus on examining the difference between talking to others about unfair treatment compared to keeping it to oneself as the predictor for coping. The purpose of this study is to examine the association between 1) talking to someone in response to unfair treatment and perceived stress and 2) talking to someone in response to unfair treatment and depressive symptoms in a cohort of African Americans. We will also examine the association between perceived stress and depressive symptoms. We hypothesize that there would be a negative association between talking and depressive symptoms, in addition to a negative association between talking and perceived stress levels. Investigating the influence of talking after unfair treatment as a coping mechanism can yield important insight as a potential mechanism to ameliorate chronic disease risk factors associated with stress and mental health conditions that disproportionately affects African Americans. Although talking should not replace treatments for depression, it could be an additional method incorporated in coping mechanisms to alleviate perceived stress and treatments for depressive symptoms in African Americans.

\section{Methods}

Data for this study were obtained from The Minority Health Genomics and Translational Research Bio-Repository Database (MH-GRID) study which was a multicohort case-control study of African Americans aged 30-55 years with optimal blood pressure and severe or resistant hypertension from the southern region of the United States. Details of the MH-GRID study design are described in detail elsewhere [31]. In this study, we focused on a subset of MH-GRID participants who were recruited from Morehouse School of Medicine (Atlanta, GA), Kaiser Permanente-Georgia (Atlanta, GA) the Grady Health System (Atlanta, GA) and the Jackson Hinds Clinic (Jackson, MS) between April 2012 and September 2013. Participants in MH-GRID signed written informed consent prior to participation in the study [31]. The original sample consisted of 490 participants, but 
after excluding participants with missing data, the sample for this study included 237 women and 139 men for a total of 376 participants. This study received approval from the Morehouse School of Medicine, Kaiser Permanente and the National Institutes of Health Institutional Review Boards, in addition to the Grady Health System Research Oversight Committee.

\section{Predictor variable}

The unfair treatment variable was derived from Krieger et. al's Experiences of Discrimination Questionnaire [32]. Response to unfair treatment was the primary predictor variable based on the yes/no question "If you have been treated unfairly, do you usually talk to people about it or keep it to yourself? The reference was "keep it to yourself". The response 'Talk to people about it' is considered active coping, and "keep it to yourself" is considered passive coping based on a similar study that used a similar classification [17]. The 'don't know/not sure' and 'refused' response categories were excluded from the analyses. Response to unfair treatment was also used as the primary predictor variable based on the question "If you have been treated unfairly, do you usually accept it as a fact of life about it or try to do something about it?" However, the results were insignificant, so they were not displayed in the analyses.

\section{Outcome variables}

The 20-item Center for Epidemiologic Studies Depression Scale (CES-D) was used to assess the presence of depressive symptoms [33]. CES-D Scale is a self-report instrument used to measure several functional domains commonly linked to depression [33]. The scale has been found as a reliable measure for assessing depressive symptoms in large-scale epidemiological studies. Participants indicated how often over the past week, they experienced each of the 20 symptoms described in the CES-D scale. Responses were made on a 4-point scale ranging from 0 (rarely or none of the time) to 3 (most of or all the time). After reverse coding for 4 items, higher scores indicate greater frequency of depressive symptoms. The Cronbach Alpha's score for the CES-D is 0.83 .

The Cohen's 14-item Perceived Stress Scale (PSS) was used as a measure of perceived stress which consisted of 14 questions related to the participant's level of exposure to perceived stress in the last month [34]. The PSS was administered by trained health professionals. Participants had to choose from $1=$ never, $2=$ almost never, $3=$ sometimes, $4=$ fairly often and $5=$ very often. Each item used the Likert scale from 1-5, but were relabeled to $0-4$ for analytical purposes. The scale was calculated by first reversing the numbers for relevant positive variables [35]. Then, all the 14 -items were summed for each participant. A high PSS value equated to higher stress and a low PSS value equated to lower stress. The Cronbach Alpha's alpha score for the PSS is 0.91 .

\section{Covariates}

Covariates included age, sex, level of education, marital status, employment status and hypertension status. Covariates used for the adjusted models were chosen based on their possible relationship with the outcome variables. Sociodemographic variables were based on self-report at the time of enrollment and hypertension was defined as a systolic blood pressure of between $\geq 140 \mathrm{~mm} \mathrm{Hg}$ and $\leq 180 \mathrm{~mm} \mathrm{Hg}$, diastolic blood pressure between $\geq 90 \mathrm{~mm} \mathrm{Hg}$ and $\leq 110 \mathrm{~mm}$ $\mathrm{Hg}$, or the use of $\geq 2$ medications for blood pressure for at least the last 3 months. Self-reported sex and age was recorded at baseline. Education was divided into three categories: 1$) \leq 12$ years or graduate equivalency diploma (GED), 2) some college/technical school and 3) college graduate or higher. Those who were classified as married included those who were separated, living with a partner and married. Those who were unmarried included participants who were widowed, divorced, or single/never married. The employed group consisted of participants who were working part-time, on leave for sick reasons, and working full time. Unemployed included participants who were retired, homemakers, looking for work, students and employed, but temporarily laid off.

\section{Statistical analysis}

Linear regression models were used to calculate the unadjusted and adjusted $\beta$ estimates for the association of talking following unfair treatment compared to keeping it to oneself on perceived stress and depressive symptoms. Linear regression models were also used to calculate the unadjusted and adjusted $\beta$ estimates for the association between perceived stress and depressive symptoms. Sex, level of education, marital status, employment status, and hypertension were entered as categorical variables and age as a continuous variable. Interactions between sociodemographic covariates and talking to other people in response to unfair treatment with both perceived stress and depressive symptoms were tested in adjusted linear regression models separately. Significance was based on a two tailed significance level of $\leq 0.05$. A $p$ value $<0.10$ was also considered as slightly significant because it can also be considered as "trending toward statistical significance" [36]. The analyses were conducted using the SAS software [37]. 


\section{Results}

Table 1 presents the descriptive characteristics of the study population and shows that the mean age was 45.84 years old. The distribution between those who completed some college/technical college and college graduate or higher was similar, however majority of participants were in the completed $\leq 12$ years or GED (36.70\%) group. There were also more women (63.03\%) than men (36.97\%). Most of the participants were unmarried $(61.97 \%)$. The percentage of those employed was higher than those unemployed (61.70\% versus $38.30 \%$, respectively) and $62.50 \%$ of respondents had hypertension. Most participants reported talking to someone in response to unfair treatment compared to a lower proportion who kept it to themselves (85.90\% vs. $14.10 \%)$. The mean depression score was 12.47 and the mean perceived stress score was 21.78 . This shows that the mean depression score was along the spectrum of the scale, while the average perceived stress score was among the lower/medium spectrum of the scale.

Table 2 reveals the unadjusted and adjusted linear regression models for the association between talking

Table 1 Descriptive characteristics of study sample, MH-GRIDa, $N=376$

\begin{tabular}{|c|c|c|}
\hline Characteristics & $\%$ & Mean $\left(\right.$ std $^{\text {b) }}$ \\
\hline Age, years & & $45.84(6.68)$ \\
\hline \multicolumn{3}{|l|}{ Sex } \\
\hline Women & $237(63.03 \%)$ & \\
\hline Men & $139(36.97 \%)$ & \\
\hline \multicolumn{3}{|l|}{ Education } \\
\hline$\leq 12$ years or $\mathrm{GED}^{c}$ & $138(36.70 \%)$ & \\
\hline Some college or technical college & $114(30.32 \%)$ & \\
\hline College graduate or higher & $124(32.98 \%)$ & \\
\hline \multicolumn{3}{|l|}{ Marital Status } \\
\hline Unmarried & $233(61.97 \%)$ & \\
\hline Married & $143(38.03 \%)$ & \\
\hline \multicolumn{3}{|l|}{ Employment status } \\
\hline Unemployed & $144(38.30 \%)$ & \\
\hline Employed & $232(61.70 \%)$ & \\
\hline \multicolumn{3}{|l|}{ Hypertension, mmHg } \\
\hline No & $141(37.50 \%)$ & \\
\hline Yes & $235(62.50 \%)$ & \\
\hline \multicolumn{3}{|l|}{ How do you respond if treated unfairly? } \\
\hline Talk to Someone About It & $323(85.90 \%)$ & \\
\hline Keep It To Themselves & $53(14.10 \%)$ & \\
\hline \multicolumn{2}{|l|}{ Perceived Stress Scale } & $21.78(8.70)$ \\
\hline \multicolumn{2}{|l|}{ Depression Scale } & $12.47(10.63)$ \\
\hline \multicolumn{3}{|c|}{$\begin{array}{l}\text { a MH-GRID Minority Health Genomics and Translational Research Bio-Repository } \\
\text { Database }\end{array}$} \\
\hline \multicolumn{3}{|l|}{ b STD standard deviation } \\
\hline \multicolumn{3}{|l|}{ ` GED Graduate Equivalency Diploma } \\
\hline
\end{tabular}

Table 2 Linear regression of the association of talking following unfair treatment on perceived stress in African Americans, $\mathrm{MH}-\mathrm{GRID}^{\mathrm{a}}, \mathrm{N}=376$

\begin{tabular}{|c|c|c|c|c|}
\hline \multirow{3}{*}{$\begin{array}{l}\text { Perceived } \\
\text { Stress Scale }\end{array}$} & \multicolumn{4}{|c|}{ Talking following unfair treatment ${ }^{b}$} \\
\hline & \multicolumn{2}{|l|}{ Unadjusted } & \multicolumn{2}{|l|}{ Adjusted $^{c}$} \\
\hline & $\begin{array}{l}\beta \text { Estimate } \\
\left(\mathrm{SE}^{\mathrm{d}}\right)\end{array}$ & $P$ value & $\begin{array}{l}\beta \text { Estimate } \\
\left(\mathrm{SE}^{\mathrm{d}}\right)\end{array}$ & $P$ value \\
\hline 14-item PSS & $-4.08(1.14)$ & $p \leq 0.05$ & $-3.62(1.14)$ & $p \leq 0.05$ \\
\hline \multicolumn{5}{|c|}{$\begin{array}{l}{ }^{a} \text { MH-GRID Minority Health Genomics and Translational Research Bio-Repository } \\
\text { Database }\end{array}$} \\
\hline \multicolumn{5}{|c|}{${ }^{\mathrm{b}}$ Compared to keeping it to themselves } \\
\hline \multicolumn{5}{|c|}{$\begin{array}{l}{ }^{c} \text { Adjusted model include age, sex, educational level, marital, employment and } \\
\text { hypertension status }\end{array}$} \\
\hline \multicolumn{5}{|c|}{${ }^{\mathrm{d}}$ SE Standard Error } \\
\hline \multicolumn{5}{|c|}{ e PSS Perceived Stress Scale } \\
\hline
\end{tabular}

following unfair treatment on the perceived stress scale. In the unadjusted model, perceived stress was reduced by 4.08 units among participants who spoke to someone following exposure to unfair treatment ( $\beta$ : -4.08 , SE: 1.14 ,$p \leq 0.05)$ and 3.4 units in the adjusted model $(\beta:-3.62$, $\mathrm{SE}: 1.14, \mathrm{p} \leq 0.05)$

Table 3 reveals that those who talked to someone following unfair treatment, compared to those who kept it to themselves, experienced a lower level of depression symptoms by 5.65 nits in the unadjusted model $(\beta$ $:-5.65$, standard error: $1.55, p \leq 0.05)$ and 3.75 units in the adjusted model ( $\beta$ : -3.75 , Standard Error: $1.45, p \leq 0.05)$.

Table 4 shows a positive association between perceived stress and depressive symptoms. In the unadjusted model, as perceived stress increases by 1 unit, depressive symptoms increased by 0.83 units $(\beta: 0.83$, SE: 0.05 ,$p<0.0001)$. In the adjusted model, as perceived stress

Table 3 Linear regression of the association of talking following exposure to unfair treatment on self-reported level of depressive symptoms in African Americans, MH-GRIDa,$N=376$

\begin{tabular}{|c|c|c|c|c|}
\hline \multirow{3}{*}{$\begin{array}{l}\text { Depression } \\
\text { Scale }\end{array}$} & \multicolumn{4}{|c|}{ Talking following unfair treatment ${ }^{b}$} \\
\hline & \multicolumn{2}{|l|}{ Unadjusted } & \multicolumn{2}{|l|}{ Adjusted $^{c}$} \\
\hline & $\begin{array}{l}\beta \text { Estimate } \\
(\mathrm{SE})^{\mathrm{d}}\end{array}$ & $P$ value & $\begin{array}{l}\beta \text { Estimate } \\
(\mathrm{SE})^{\mathrm{d}}\end{array}$ & $P$ value \\
\hline $\begin{array}{l}\text { 20-item CES-D } \\
\text { Scale }\end{array}$ & $-5.65(1.55)$ & $p \leq 0.05$ & $-3.75(1.45)$ & $p \leq 0.05$ \\
\hline \multicolumn{5}{|c|}{$\begin{array}{l}{ }^{a} M H-G R I D \text { Minority Health Genomics and Translational Research Bio-Repository } \\
\text { Database }\end{array}$} \\
\hline \multicolumn{5}{|c|}{$\begin{array}{l}{ }^{c} \text { Adjusted model include age, sex, educational level, marital, employment and } \\
\text { hypertension status }\end{array}$} \\
\hline \multicolumn{5}{|c|}{${ }^{\mathrm{d}}$ SE Standard Error } \\
\hline \multicolumn{5}{|c|}{ e CES-D Scale Center for Epidemiologic Studies Depression Scale } \\
\hline
\end{tabular}


Table 4 Linear regression of the association of perceived stress and self-reported level of depressive symptoms in African Americans, $\mathrm{MH}-\mathrm{GRID}^{\mathrm{a}}, \mathrm{N}=376$

\begin{tabular}{|c|c|c|c|c|}
\hline \multirow[t]{3}{*}{ Depression Scale } & \multicolumn{4}{|l|}{ PSS $^{b}$} \\
\hline & \multicolumn{2}{|l|}{ Unadjusted } & \multicolumn{2}{|l|}{ Adjusted $^{c}$} \\
\hline & $\begin{array}{l}\beta \text { Estimate } \\
(\mathrm{SE})^{\mathrm{d}}\end{array}$ & $P$ value & $\begin{array}{l}\beta \text { Estimate } \\
(\mathrm{SE})^{\mathrm{d}}\end{array}$ & $P$ value \\
\hline $\begin{array}{l}\text { 20-item CES-D } \\
\text { Scale }^{\mathrm{e}}\end{array}$ & $0.83(0.05)$ & $p<0.0001$ & $0.76(0.05)$ & $p<0.0001$ \\
\hline \multicolumn{5}{|c|}{$\begin{array}{l}\text { a MH-GRID Minority Health Genomics and Translational Research Bio-Repository } \\
\text { Database }\end{array}$} \\
\hline \multicolumn{5}{|c|}{$\begin{array}{l}{ }^{b} \text { Adjusted models include age, sex, educational level, marital, employment and } \\
\text { hypertension status }\end{array}$} \\
\hline \multicolumn{5}{|l|}{ 'SE Standard Error } \\
\hline \multicolumn{5}{|c|}{ d PSS Perceived Stress Scale } \\
\hline \multicolumn{5}{|c|}{ e CES-D Scale Center for Epidemiologic Studies Depression Scale } \\
\hline
\end{tabular}

increases by 1 unit, depressive symptoms increased by 0.76 units ( $\beta$ : 0.76 , SE: $0.05,-p<0.0001)$.

There was only a slight significant interaction with a $p$ value $\leq 0.10$ between employment status and the talking variable when the outcome was CES-D symptoms $(p=0.0974)$. Also, there was only a borderline significant interaction with a $p$ value $\leq 0.10$ between employment status and talking to other people in response to unfair with the outcome for perceived stress scale $(p=0.0761)$. Therefore, descriptive results stratified by employment status and results of linear regression models stratified by employment status are presented in the Additional File 1: Tables S1, S2 and S3.

\section{Discussion}

This study revealed the association between talking with someone in response to unfair treatment on level of perceived stress and depressive symptoms among African Americans. Participants who talked with someone about their unfair treatment had less perceived stress and depressive symptoms. There was also a positive association between depressive symptoms and perceived stress. These findings suggest that talking to someone about experiences of unfair treatment may have a positive association between reducing stress and depressive symptoms in African Americans.

These results align with previous studies that have shown that talking to others about stressors can also help with adjusting to stressors [26]. This was shown to be true among a group of undergraduate students. In this experiment, those that had the option to speak with someone about the stressor had lower levels of perceived stress after being exposed to the stressor compared to those who were not able to speak to anyone [26]. Another study that included talking to someone about worries under the scope of emotional social support concluded that there was an inverse relationship between satisfaction with emotional social support and stress levels among African Americans [38]. Despite these findings, there is mixed evidence on the association between social support and perceived stress levels. In this same study, African Americans who had more emotional social support also had higher stress levels, which may be because people seek out more social support when they are experiencing more stressful circumstance [38]. In a different study, those that sought advice from friends and professionals were in more distress than those who did not ask for advice but had the same problems [28].

Additionally, although the focus of this paper is not on psychotherapy, rather than focusing on the broad scope of social support we focused on one specific aspect of social support--talking. Many studies have examined the role of social support on depressive symptoms or perceived stress in African Americans, but only a few have solely looked at the role of talking to someone [39-41]. The role of talking on depressive symptoms has been studied before within a sample of pregnant African American women [42]. Those who experienced unfair treatment and kept it to themselves had a greater odd of elevated depressive symptoms, compared to those that talked to others [42]. Those who talked to others while also doing something about it had the lowest odds of elevated depression symptoms [42].

In this project, the results align with those of Ertzel et al., 2012, but differs in that it includes both African American men and women [42]. In regards to perceived stress, a 2009 study showed that social support, which includes reaching out and talking to people, was a mediator for the effects of perceived racism on mental and physical health in African Americans; the study, however, did not assess exposure to unfair treatment [43]. Another study that examined a sample of 4,000 African American and White participants showed that $69 \%$ of African Americans would do something and talk to others in response to exposure to stressful racism [44]. In this project, a further step was taken by assessing talking to someone in response to unfair treatment and to examine the association between the variable that represented talking and perceived stress.

In addition, this project showed a significant relationship between perceived stress and depressive symptom among African Americans. Many previous studies have examined this relationship, but there aren't as many focused on African Americans [45-47]. One study that focused on older African Americans showed a correlation between depression symptoms and perceived stress [30]. However, many studies show an association between certain stressors, like discrimination, on depressive 
symptoms, but not as many have focused on the association between perceived stress and depressive symptoms among African Americans [48, 49]. The purpose of examining this relationship was to show that creating initiatives to reduce depressive symptoms could also indirectly mitigate perceived stress or creating initiatives to reduce perceived stress could also mitigate depressive symptoms in African Americans. Understanding this relationship helps explain why the results in this study showed an association between talking and both perceived stress and depressive symptoms.

Lastly, this project also revealed a marginal significant interaction between employment status and response to unfair treatment when the outcome was either depression or stress. There is more research on coping and workplace stress than the association between employment status and perceived stress in African Americans $[50,51]$. There is also mixed evidence on the association between employment status and depression in African Americans in the literature [52-55]. These differing conclusions on the relationship between employment status and depression don't explain why the results revealed that African Americans who are employed had lower levels of depression when they spoke to others in response to unfair treatment, but African Americans who were unemployed did not have significantly lower depression levels if they spoke to others in response to unfair treatment. Perhaps, due to other health and social factors, such as lack of access to health care and financial instability, these are bigger contributors to their depression as suggested by a study that showed retired African American men may have greater rates of depression than White men because they could face greater sociocultural barriers [56]. However, this project suggests the need for more research that investigates effective methods to reduce depressive symptoms and perceived stress among unemployed African Americans.

Despite these findings, the study has several limitations including the disproportionate group sizes, the use of other medications, regional effects and the crosssectional analyses in this study. The sample size of those who keep it to themselves is much smaller than the sample of those who talk following unfair treatment which may result in selection bias (14.7\% vs $85.7 \%)$. Future research should replicate this study with a larger sample size within the group of people who kept it to themselves after unfair treatment in order to confirm results. There was also no evaluation of whether participants currently attended therapy, engaged in coping mechanisms for stress regularly or were currently using treatments for depression because the variable was not available. The use of antidepressant medication could affect the results. If certain patients were taking medications that may affect their mood, their reduced level of depression could be due to that medication instead of talking to others after unfair treatment. Additionally, there is a lack of generalizability because the findings are based on African Americans residing in the southern region of the United States. Although we expect similar findings among African Americans residing in other regions of the country.

\section{Conclusions}

Overall, the findings suggest that African Americans who reported that they usually talk to others following perceived unfair treatment had lower perceived stress and less depressive symptoms compared with those who reported that they keep the experience of unfair treatment to themselves. With depression levels on the rise in the United States from 2005 to 2015, there is an urgent need for more studies that examine not only depression in African Americans but also create interventions to prevent depression in African Americas [57]. Continually examining ways to reduce the depressive symptoms rates in African Americans could also indirectly reduce MDD disparities that exist in the United States. Talking about unfair treatment with others may also be a mechanism to help mitigate stress-induced adverse health conditions in African Americans. More public resources should be allocated towards outreach to African Americans regarding the importance of talking in response to unfair treatment as a potential coping mechanism. Future research should also examine additional coping mechanisms to unfair treatment and its potential to ameliorate chronic disease risk factors and mental health conditions such as depression and stress in African Americans.

\section{Abbreviations}

MH-GRID: Minority Health Genomics and Translational Research Bio-Repository Database; CES-D: Center for Epidemiologic Studies Depression Scale; PSS: Perceived Stress Scale; GED: Graduate Equivalency Diploma.

\section{Supplementary Information}

The online version contains supplementary material available at https://doi. org/10.1186/s12888-022-03772-y.

\section{Additional file 1.}

\section{Acknowledgements}

This project was supported by the Intramural Research Program of the NIH, National Human Genome Research Institute and editorial assistance was provided by the NIH Fellows Editorial Board.

\section{Authors' contributions}

$\mathrm{AO}$ analyzed the data and wrote the entire manuscript. Every author reviewed the entire manuscript, but some authors contributed more to certain sections than others. SD and $\mathrm{RQ}$ reviewed the entire manuscript and left edits/ corrects for every section of the entire manuscript. AG edited the methods and results section of the manuscript. RX, RK, and LD also mainly focused on leaving comments and edits for the methods section. $\mathrm{KB}$ and $J \mathrm{~L}$ also reviewed 
and left edits for the entire manuscript, but they mainly contributed to the introduction and discussion section. The author(s) read and approved the final manuscript.

\section{Funding}

Not Applicable.

\section{Availability of data and materials}

The datasets used and/or analyzed during the current study are available from the corresponding author on reasonable request.

\section{Declarations}

\section{Ethics approval and consent to participate}

This study received approval from the Morehouse School of Medicine, Kaiser Permanente and the National Institutes of Health Institutional Review Boards, in addition to the Grady Health System Research Oversight Committee.

\section{Consent for publication}

Not Applicable.

\section{Competing interests}

The authors declare that they have no competing interests.

\section{Author details}

${ }^{1}$ University of Minnesota Medical Scientist Training Program, 420 Delaware St SE, Minneapolis, MN 55455, USA. ${ }^{2}$ Social Epidemiology Research Unit, National Institutes of Health, National Human Genome Research Institute, Bethesda, USA. ${ }^{3}$ Cardiovascular Research Institute, Morehouse School of Medicine, Atlanta, GA, USA

Received: 1 July 2021 Accepted: 9 February 2022

Published online: 21 February 2022

\section{References}

1. Lewis TT, Cogburn CD, Williams DR. Self-reported experiences of discrimination and health: scientific advances, ongoing controversies, and emerging issues. Annu Rev Clin Psychol. 2015;11:407-40.

2. Assari S, Moazen-Zadeh E, Caldwell CH, Zimmerman MA. Racial discrimination during adolescence predicts mental health deterioration in adulthood: Gender differences among Blacks. Front Public Health. 2017;5:104.

3. Rej PH. HEAT Steering Committee, Gravlee CC, Mulligan CJ. Shortened telomere length is associated with unfair treatment attributed to race in African Americans living in Tallahassee, Florida American Journal of Human Biology. 2020;32(3):e23375.

4. Beatty $\mathrm{DL}$, Matthews KA. Unfair treatment and trait anger in relation to nighttime ambulatory blood pressure in African American and white adolescents. Psychosom Med. 2009;71(8):813.

5. McFarland MJ, Taylor J, McFarland CA, Friedman KL. Perceived unfair treatment by police, race, and telomere length: a nashville community-based sample of black and white men. J Health Soc Behav. 2018;59(4):585-600.

6. Beatty DL, Hall MH, KamarckTA, Buysse DJ, Owens JF, Reis SE, Mezick EJ, Strollo PJ, Matthews KA. Unfair treatment is associated with poor sleep in African American and Caucasian adults: Pittsburgh SleepSCORE project. Health Psychol. 2011;30(3):351

7. Ong AD, Williams DR, Nwizu U, Gruenewald TL. Everyday unfair treatment and multisystem biological dysregulation in African American adults. Cultur Divers Ethnic Minor Psychol. 2017;23(1):27.

8. Guyll M, Matthews KA, Bromberger JT. Discrimination and unfair treatment: relationship to cardiovascular reactivity among African American and European American women. Health Psychol. 2001;20(5):315.

9. Schulz A, Williams D, Israel B, Becker A, Parker E, James SA, Jackson J. Unfair treatment, neighborhood effects, and mental health in the Detroit metropolitan area. J Health Soc Behav. 2000;1:314-32.

10. Kennedy B R, Mokonogho J, Kumar A. Racial and ethnic differences in depression: current perspectives. Neuropsychiatric disease and treatment. 2019:15:603.
11. Bains, Navneet, and Sara Abdijadid. "Major depressive disorder." StatPearls [Internet] (2020)

12. Hannon, Christine R. "Stress, Coping, and well being of African American college women: a grounded theory study." (2016).

13. Brenner AB, Diez-Roux AV, Gebreab SY, Schulz AJ, Sims M. The epidemiology of coping in African American adults in the Jackson Heart Study (JHS)." Journal of racial and ethnic health disparities. Journal of racial and ethnic health disparities. 2018;5(5):978-94 Griffin, Eugena K., and Cheryl Armstead. "Black's Coping Responses to Racial Stress."(2020): 1-10.

14. Armstrong-Mensah Elizabeth, Bills Rebekah, Reyes Lizbeth. Culture, Depression, and Coping Mechanisms among African Americans. Research in Health Sciences. 2020;5(3):p102.

15. Greer TM. Coping strategies as moderators of the relation between individual race-related stress and mental health symptoms for African American women. Psychol Women Q. 2011;35(2):215-26.

16. Wright ML, Lim S, Sales A, Rajagopal S, Nzegwu D, Crusto CA, Taylor JY. The Influence of Discrimination and Coping Style on Blood Pressure Among Black/African American Women in the InterGEN Study. Health Equity. 2020;4(1):272-9.

17. Dyke ML, Cuffee YL, Halanych JH, McManus RH, Curtin C, Allison JJ. The relationship between coping styles in response to unfair treatment and understanding of diabetes self-care. Diabetes Educ. 2013;39(6):848-55.

18. Clark R, Anderson NB. Efficacy of racism-specific coping styles as predictors of cardiovascular functioning. Ethn Dis. 2001;11(2):286-95.

19. Hill LK, Hoggard LS. Active coping moderates associations among racerelated stress, rumination, and depressive symptoms in emerging adult African American women. Dev Psychopathol. 2018;30(5):1817.

20. Sohail Z, Bailey RK, Richie WD. Misconceptions of depression in African Americans. Front Psych. 2014;5:65.

21. Jones MK, Hill-Jarrett TG, Latimer K, Reynolds A, Garrett N, Harris I, Joseph S, Jones A. The Role of Coping in the Relationship Between Endorsement of the Strong Black Woman Schema and Depressive Symptoms Among Black Women. J Black Psychol. 2021;9:00957984211021229.

22. Utsey SO, Bolden MA, Williams O III, Lee A, Lanier Y, Newsome C. Spiritual well-being as a mediator of the relation between culture-specific coping and quality of life in a community sample of African Americans. J Cross Cult Psychol. 2007;38(2):123-36.

23. Griner D, Smith TB. Culturally adapted mental health intervention: A meta-analytic review. Psychotherapy: Theory, research, practice, training. 2006;43(4):531.

24. Health Quality Ontario. Psychotherapy for major depressive disorder and generalized anxiety disorder a health technology assessment. Ontario health technology assessment series. 2017;17(15):1-167.

25. Chung B, Corbett CE, Boulet B, Cummings JR, Paxton K, McDaniel S, Mercier SO, Franklin C, Mercier E, Jones L, Collins BE. Talking Wellness: a description of a community-academic partnered project to engage an African-American community around depression through the use of poetry, film, and photography. Ethn Dis. 2006;16(1 Suppl 1):S67-78.

26. Lepore SJ, Ragan JD, Jones S. Talking facilitates cognitive-emotional processes of adaptation to an acute stressor. J Pers Soc Psychol. 2000;78(3):499.

27. American Psychological Association. "Social Support". https://dictionary. apa.org/social-support. Assessed 14 April 2021

28. Shim RS, Ye J, Baltrus P, Fry-Johnson Y, Daniels E, Rust G. Racial/ethnic disparities, social support, and depression: examining a social determinant of mental health. Ethn Dis. 2012;22(1):15.

29. Griner D, Smith TB. Culturally adapted mental health intervention: A meta-analytic review. Psychotherapy: Theory, research, practice, training. 2006:43(4):531.

30. Benca-Bachman CE, Najera DD, Whitfield KE, Taylor JL, Thorpe RJ Jr, Palmer $\mathrm{RH}$. Quality and quantity of social support show differential associations with stress and depression in African Americans. Am J Geriatr Psychiatry. 2020;28(6):597-605.

31. Gaye A, Doumatey AP, Davis SK, Rotimi CN, Gibbons GH. Wholegenome transcriptomic insights into protective molecular mechanisms in metabolically healthy obese African Americans. NPJ Genom Med. 2018;3(1):1-8

32. Krieger N, Smith K, Naishadham D, Hartman C, Barbeau EM. Experiences of discrimination: validity and reliability of a self-report measure for population health research on racism and health. Soc Sci Med. 2005:61(7):1576-96. 
33. Carleton RN, Thibodeau MA, Teale MJ, Welch PG, Abrams MP, Robinson T, Asmundson GJ. The center for epidemiologic studies depression scale: a review with a theoretical and empirical examination of item content and factor structure. PloS one. 2013;8(3):e58067.

34. Cohen S. Perceived stress in a probability sample of the United States. 1988.

35. Gazzaz ZJ, Baig M, Al Alhendi BS, Al Suliman MM, Al Alhendi AS, Al-Grad MS, Qurayshah MA. Perceived stress, reasons for and sources of stress among medical students at Rabigh Medical College, King Abdulaziz University, Jeddah. Saudi Arabia BMC medical education. 2018;18(1):1-9.

36. Thiese MS, Ronna B, Ott U. P value interpretations and considerations. J Thorac Dis. 2016;8(9):E928.

37. SAS Institute Inc. 2013. SAS ${ }^{\circledR} 9.4$ Statements: Reference. Cary, NC: SAS Institute

38. Benca-Bachman CE, Najera DD, Whitfield KE, Taylor JL, Thorpe RJ Jr, Palmer $\mathrm{RH}$. Quality and quantity of social support show differential associations with stress and depression in African Americans. Am J Geriatr Psychiatry. 2020;28(6):597-605

39. Heard E, Whitfield KE, Edwards CL, Bruce MA, Beech BM. Mediating effects of social support on the relationship among perceived stress, depression, and hypertension in African Americans. J Natl Med Assoc. 2011;103(2):116-22.

40. Qin W, Nguyen AW, Mouzon DM, Hamler TC, Wang F. Social support, everyday discrimination, and depressive symptoms among older African Americans: A longitudinal study. Innovation in Aging. 2020;4(5):igaa032.

41. Chung B, Corbett CE, Boulet B, Cummings JR, Paxton K, McDaniel S, Mercier SO, Franklin C, Mercier E, Jones L, Collins BE. Talking Wellness: a description of a community-academic partnered project to engage an African American community around depression through the use of poetry, film, and photography. Ethn Dis. 2006;16(1 Suppl 1):S67-78.

42. Ertel KA, James-Todd T, Kleinman K, Krieger N, Gillman M, Wright $R$, Rich-Edwards J. Racial discrimination, response to unfair treatment, and depressive symptoms among pregnant black and African American women in the United States. Ann Epidemiol. 2012;22(12):840-6.

43. Brondolo E, Ver Halen NB, Pencille M, Beatty D, Contrada RJ. Coping with racism: A selective review of the literature and a theoretical and methodological critique. J Behav Med. 2009;32(1):64-88.

44. Greer TM. Coping strategies as moderators of the relation between individual race-related stress and mental health symptoms for African American women. Psychol Women Q. 2011;35(2):215-26.

45. McHugh RK, Sugarman DE, Meyer L, Fitzmaurice GM, Greenfield SF. The relationship between perceived stress and depression in substance use disorder treatment. Drug and alcohol dependence. 2020;207:107819.

46. Wei L, Sha T. The relationship between perceived stress and depression and anxiety in college students: The effect of social support. Chinese Journal of Clinical Psychology. 2003 May.

47. Ghorbani N, Krauss SW, Watson PJ, LeBreton D. Relationship of perceived stress with depression: Complete mediation by perceived control and anxiety in Iran and the United States. Int J Psychol. 2008;43(6):958-68.

48. Wheaton FV, Thomas CS, Roman C, Abdou CM. Discrimination and depressive symptoms among African American men across the adult lifecourse. The Journals of Gerontology: Series B. 2018;73(2):208-18.

49. Williams DR. Stress and the mental health of populations of color: Advancing our understanding of race-related stressors. J Health Soc Behav. 2018;59(4):466-85.

50. Mays VM, Coleman LM, Jackson JS. Perceived race-based discrimination, employment status, and job stress in a national sample of black women: implications for health outcomes. J Occup Health Psychol. 1996;1(3):319.

51. Hall JC, Everett JE, Hamilton-Mason J. Black women talk about workplace stress and how they cope. J Black Stud. 2012;43(2):207-26.

52. Agarwal M, Hamilton JB, Moore CE, Crandell JL. Predictors of depression among older African American cancer patients. Cancer Nurs. 2010;33(2):156-63. https://doi.org/10.1097/NCC.0b013e3181bdef76.

53. Holden KB, Bradford LD, Hall SP, Belton AS. Prevalence and correlates of depressive symptoms and resiliency among African American women in a community-based primary health care center. J Health Care Poor Underserved. 2013;24(4 0):79-93. https://doi.org/10.1353/hpu.2014.0012.

54. Ward E, Mengesha M. Depression in African American men: A review of what we know and where we need to go from here. American Journal of Orthopsychiatry. 2013;83(2pt3):386-97.
55. Rodriguez E, Allen JA, Frongillo EA, Chandra P. Unemployment, depression, and health: a look at the African-American community. J Epidemiol Community Health. 1999;53(6):335-42.

56. Ward E, Mengesha M. Depression in African American men: A review of what we know and where we need to go from here. Am J Orthopsychiatry. 2013;83(2 Pt 3):386-97. https://doi.org/10.1111/ajop.12015.

57. Weinberger AH, Gbedemah M, Martinez AM, Nash D, Galea S, Goodwin RD. Trends in depression prevalence in the USA from 2005 to 2015: widening disparities in vulnerable groups. Psychol Med. 2018;48(4):1308-15. https://doi.org/10.1017/S0033291717002781.

\section{Publisher's Note}

Springer Nature remains neutral with regard to jurisdictional claims in published maps and institutional affiliations.
Ready to submit your research? Choose BMC and benefit from:

- fast, convenient online submission

- thorough peer review by experienced researchers in your field

- rapid publication on acceptance

- support for research data, including large and complex data types

- gold Open Access which fosters wider collaboration and increased citations

- maximum visibility for your research: over $100 \mathrm{M}$ website views per year

At $\mathrm{BMC}$, research is always in progress.

Learn more biomedcentral.com/submissions 